\title{
Radiotherapy alone for stage IE ocular adnexal mucosa-associated lymphoid tissue lymphomas: long-term results
}

\author{
Masanari Niwa', Satoshi Ishikura ${ }^{1 *}$ (D), Kotoha Tatekawa², Natsuko Takama ${ }^{3}$, Akifumi Miyakawa ${ }^{3}$, Toshinobu Kubota ${ }^{4}$,
} Eriko Kato ${ }^{3}$ and Yuta Shibamoto ${ }^{1}$

\begin{abstract}
Background: To evaluate the long-term efficacy and toxicity of radiation therapy in patients with Stage IE primary ocular adnexal mucosa-associated lymphoid tissue lymphoma.

Methods: We designed a retrospective analysis to evaluate 81 patients with ocular adnexal mucosa-associated lymphoid tissue lymphoma treated with radiation therapy between 2006 and 2016. The median radiation dose was 30 Gy (range, 30-36 Gy in 15-18 fractions). Local control, progression-free survival, overall survival, and cumulative incidence of Grade 3 cataract were calculated by using the Kaplan-Meier method.

Result: The median follow-up time was 74 months (range, 4-157 months). The 5-year local control was 100\%. Although local relapse was suspected in 3 patients after radiation therapy, 2 patients were pathologically diagnosed as IgG4-related inflammation and in 1 patient as intense inflammatory cell infiltration. The 5-year progression-free survival was $94.4 \%$. Five patients had relapse at distant sites. The 5 -year overall survival was $98.8 \%$. Twenty patients had Grade 3 cataract. The 5 -year cumulative incidences of Grade $\geq 3$ and Grade $\geq 2$ cataract for 58 patients treated without a lens shield were 38 and $40 \%$, respectively. The incidence of Grade $\geq 3$ cataract was $42 \%$ for 50 patients treated with 6-MV X-rays (estimated lens dose: $29 \mathrm{~Gy}$ ) and 17\% for 8 patients treated with 9-MeV electrons (estimated lens dose: $24 \mathrm{~Gy}$ ).

Conclusions: Radiation therapy alone yielded excellent local control and long-term survival in Stage IE ocular adnexal mucosa-associated lymphoid tissue lymphoma. Long-term observation with careful attention to relapse at distant sites is necessary. In the case of suspected local relapse, lgG4-related disease should be carefully ruled out.
\end{abstract}

Keywords: Ocular adnexal, MALT lymphoma, Radiation therapy, Cataract

\section{Background}

The concept of mucosa-associated lymphoid tissue (MALT) lymphoma was originally described by Isaacson and Wright [1] in 1983, but it was not recognized at that time. Thereafter, the distinct clinical-pathological and molecular features of MALT lymphoma were gradually accepted. MALT lymphoma is now classified as extranodal marginal zone B-cell lymphoma in the World Health Organization (WHO) classification [2, 3]. MALT lymphoma

\footnotetext{
* Correspondence: sishikur@med.nagoya-cu.ac.jp

${ }^{1}$ Department of Radiology, Nagoya City University Graduate School of Medical Sciences, 1 Kawasumi, Mizuho-cho, Mizuho-ku, Nagoya 467-8601, Japan

Full list of author information is available at the end of the article
}

is the commonest marginal zone B-cell lymphoma and accounts for $5-8 \%$ of all B-cell lymphomas [4, 5]. MALT lymphoma occurs in the ocular adnexa, salivary gland, thyroid gland, lung, breast, stomach, and colon. The most common site of MALT lymphoma is the stomach [6, 7]. Several factors associated with MALT lymphoma have been identified including infectious microorganisms, particularly Helicobacter pylori, related to gastric MALT lymphoma [8, 9]. Recently, Chlamydia psittaci infection has been identified as a pathogenesis of ocular adnexal MALT lymphoma [10]. Chlamydia psittaci not only induces lymphoid proliferation, but also seems to be responsible for chromosomal aberration, probably due to its mitogenic activity or indirectly induced oxidative damage. The incidence of ocular adnexal

(C) The Author(s). 2020 Open Access This article is distributed under the terms of the Creative Commons Attribution 4.0 International License (http://creativecommons.org/licenses/by/4.0/), which permits unrestricted use, distribution, and 
MALT lymphoma is rapidly increasing, with annual rates $\geq 6 \%$, with no evidence of peaking [11].

Several treatment modalities exist for MALT lymphoma. In general, MALT lymphoma is a radiosensitive disease [12, 13]. For non-gastric MALT, radiation therapy (RT) is considered when symptomatic [14-17]. Other therapeutic options for ocular adnexal MALT lymphoma include systemic chemotherapy, surgery alone, and "watch and wait" strategy, but none are standard [18]. Recently, the efficacy of antibiotic therapy has been reported in localized ocular adnexal MALT lymphoma associated with Chlamydia psittaci infection [10]. Although RT alone for this disease achieves excellent tumor control, cataract is the most common and serious late morbidity [19]. RT alone can result in long-term complications such as dry eye syndrome and subsequent keratitis, and they cause a serious decline in quality of life [20]. Since there are only a few well-documented reports of the efficacy and morbidity of RT in this disease, we report herein our experience with ocular adnexal MALT lymphomas that were treated with involved-field RT with long-term results.

\section{Methods}

\section{Patients}

This was a retrospective, observational case study approved by the institutional review board. We reviewed the charts of 81 patients with a biopsy-proven diagnosis of ocular adnexal MALT lymphoma between 2006 and 2016 at a single institution. Patients with transformed lymphoma component at diagnosis were excluded. All patients had Stage IE disease. Staging assessments included blood test, positron emission tomography-computed tomography (PET-CT), bone marrow aspiration, and gastroscopy. There were 42 men and 39 women, and their median age at the start of RT was 66 years (range, 29-90 years). Among the 81 patients, 57 had a tumor located in the orbit, 21 had a tumor in the conjunctiva, and 3 had a lacrimal gland tumor. Bilateral orbital involvement was observed in 9 patients.

\section{Radiotherapy}

All patients were treated with RT alone. The clinical target volume (CTV) of all patients included the entire orbit of the affected side. The planning target volume (PTV) included the CTV with a 5-mm margin. The median radiation dose was 30 Gy (range, 30-36 Gy in 1518 fractions).

Six-MV photon beams with a wedged pair of fields were used for 50 patients. Nine-MeV electron beams with a single anterior field were used for 26 patients, and a $16-\mathrm{MeV}$ electron beam was used for 1 patient. Combinations of $6-\mathrm{MV}$ photon and $9-\mathrm{MeV}$ electron beams were used for 4 patients. Nineteen patients were treated with a lead lens block. Nine patients with bilateral lesions were treated simultaneously.

\section{Follow-up evaluation and statistical analysis}

At follow-up visits, physical examinations and blood tests were performed. PET-CT was performed at least once every 5 years. RT-related adverse events were graded according to the National Cancer InstituteCommon Terminology Criteria for Adverse Events (NCI-CTCAE, version 4.0). Cataract Grade 2 was defined as symptomatic with moderate decrease in visual acuity, and Grade 3 was defined as symptomatic with marked decrease in visual acuity or operative intervention indicated. The endpoints of our study were local control (LC), progression-free survival (PFS), overall survival (OS), and incidence of adverse events calculated from the date of starting RT to the event. The rates were calculated using the Kaplan-Meier method. Differences in the incidence of cataract between the X-ray and electron beam groups were examined using the log-rank test. Local relapse was considered as an event for LC. First progression and death from any cause were considered as an event for PFS, and death from any cause for OS. Complications were graded according to the Common Terminology Criteria for Adverse Events Version 4. All statistical analyses were performed using EZR (Saitama Medical Center, Jichi Medical University, Saitama, Japan), which is a graphical user interface for R (The R Foundation for Statistical Computing, Vienna, Austria). More precisely, it is a modified version of $\mathrm{R}$ commander designed to add statistical functions frequently used in biostatistics [21].

\section{Results}

Patient characteristics are shown in Table 1. Two patients had surgery before RT. One underwent an excision of tumor and the other underwent a conjunctival resection. No patients received cytotoxic chemotherapy or antibiotics before or during RT. The median follow-

Table 1 Patient characteristics

\begin{tabular}{ll}
\hline Characteristic & No. of patients \\
\hline Sex & 42 \\
Male & 39 \\
Female & \\
Median age (range) at the start of RT, years & 66 (29-90) \\
Bilateral presentation & 9 \\
Primary site & \\
Orbit & 57 \\
Conjunctiva & 21 \\
Lacrimal gland & 3 \\
\hline
\end{tabular}


up period was 74 months (range, $4-157$ months). Fiftyfour patients had a complete follow-up of 5 years. Of the 81 patients, 56 had a complete response, 15 had a partial response, and 3 had a stable disease. In 7 patients, their responses could not be classified, but none had a progressive disease. The plots of LC, PFS, and OS are shown in Fig. 1. The 5-year LC was 100\% (Fig. 1). Although local relapse was suspected in 3 patients after RT, 2 patients were pathologically diagnosed with IgG4-related inflammation and 1 patient with intense inflammatory cell infiltration. One of the 2 patients diagnosed with IgG4-related inflammation was observed without treatment and has shown no progression. The other had nodules in the right parotid gland and right lung 4 years after being diagnosed with IgG4-related inflammation, which were pathologically diagnosed as diffuse large Bcell lymphoma (DLBCL); the patient maintains complete response with chemotherapy consisting of rituximab, cyclophosphamide, doxorubicin hydrochloride, vincristine, and prednisolone (R-CHOP). The patient diagnosed with intense inflammatory cell infiltration has shown no progression.

The 5-year PFS was 94.4\% (Fig. 1). Table 2 summarizes the clinical courses of 5 patients who had relapse at distant sites. The median time to relapse was 42 months. The relapses occurred at various sites including the contralateral conjunctiva, parotid gland, cervix, lung, intraperitoneal cavity, and femur. Of these 5 patients, 3 were treated with chemotherapy. Two of the 3 patients were treated with R-CHOP and have maintained complete response. The other patient was treated with one course of R-CHOP but chemotherapy was then switched to rituximab alone due to hemorrhagic cystitis and ileus. She subsequently had a relapse in the mediastinum and was treated with rituximab and 5fluorouracil, and she has maintained complete response for 30 months. The other 2 patients who did not receive chemotherapy have been observed without treatment and shown no further progression.

The 5 -year OS was $98.8 \%$ (Fig. 1). There were five deaths. Three of the five deaths were due to unrelated causes (gastric cancer, exacerbation of interstitial pneumonia, and choking on food, respectively). Of the remaining two, one was found to have died in the prognostic survey and the other was found dead at home; reasons for the deaths in these patients were unknown. There were no deaths due to MALT lymphoma relapse or treatment complications.

One patient incidentally had retinal detachment during RT and then underwent surgery. A lens block used was an external eye shield. The tumor was in the conjunctiva around the cornea and not massive. It was apart from the retina. Thus, we concluded that the retinal detachment was not related to the RT technique or tumor

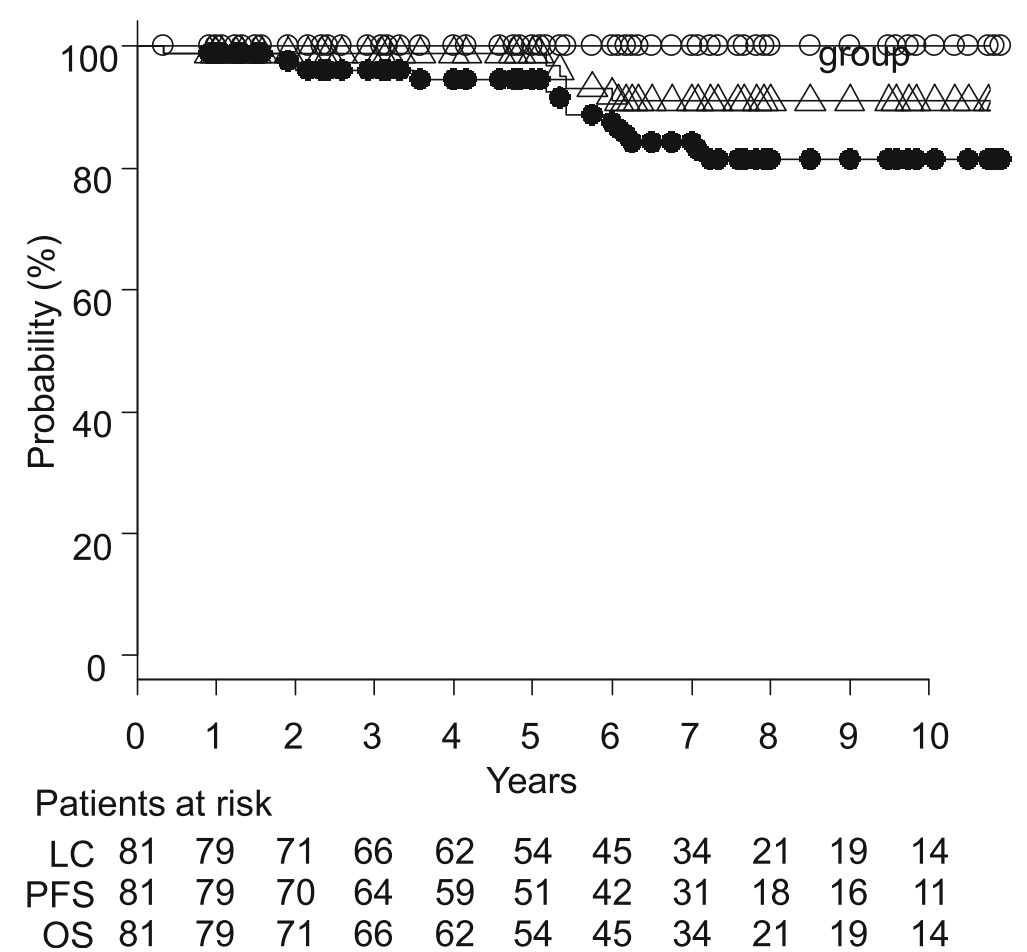

Fig. 1 Curves of local control (LC, open circle), progression-free survival (PFS, filled circle), and overall survival (OS, triangle) for 81 patients with orbital MALT lymphoma 
Table 2 Details of 5 patients with distant relapse

\begin{tabular}{|c|c|c|c|c|}
\hline $\begin{array}{l}\text { Age (years)/ } \\
\text { sex }\end{array}$ & $\begin{array}{l}\text { Primary tumor } \\
\text { site }\end{array}$ & Recurrence at distant sites & $\begin{array}{l}\text { Years to recurrence/ follow-up } \\
\text { (years)/status }\end{array}$ & $\begin{array}{l}\text { Treatment/local } \\
\text { status }\end{array}$ \\
\hline $71 / M$ & Orbit & Contralateral conjunctiva & 6.2/6.3/alive & $\begin{array}{l}\text { Observation/no } \\
\text { change }\end{array}$ \\
\hline $69 / F$ & Orbit & $\begin{array}{l}\text { Fossa axillaris, hilum of lung, mediastinal lymph node, } \\
\text { peritoneum }\end{array}$ & 2/10.3/alive & $\begin{array}{l}\mathrm{R}-\mathrm{CHOP} \\
\rightarrow \text { rituximab alone/ } \\
\mathrm{CR} \\
\rightarrow \text { relapse (8 years } \\
\text { later) }\end{array}$ \\
\hline $52 / F$ & Conjunctiva & Contralateral conjunctiva & 7.1/12.3/alive & $\begin{array}{l}\text { Observation/no } \\
\text { change }\end{array}$ \\
\hline $67 / M$ & Conjunctiva & Intestinal membrane, skin & 1.8/7.7/alive & $\mathrm{R}-\mathrm{CHOP} / \mathrm{CR}$ \\
\hline $63 / M$ & Conjunctiva & Left hilus of kidney & 3.7/10.3/alive & $\mathrm{R}-\mathrm{CHOP} / \mathrm{CR}$ \\
\hline
\end{tabular}

Abbreviations: $M$ male, $F$ female, $C R$ complete response; $\mathrm{R}-\mathrm{CHOP}=$ rituximab, cyclophosphamide, doxorubicin hydrochloride, vincristine, and prednisolone

shrinkage. There were no other Grade $\geq 3$ acute morbidities. Nine patients had Grade 2 late morbidity (dry eye, 3; superficial punctate keratitis, 4; cataract, 2). Twenty patients had Grade 3 cataract. Otherwise there were no Grade $\geq 3$ late adverse events. We excluded patients diagnosed with age-related cataracts and patients diagnosed with bilateral cataracts at the same time after RT to one side. The 5-year cumulative incidences of Grade $\geq$ 3 and Grade $\geq 2$ cataract for 58 patients treated with 6MV X-rays or $9 \mathrm{MeV}$ electrons without a lens shield were $38 \%$ (95\% confidence interval [CI], 22-51\%) and $40 \%$ (95\% CI, 24-53\%), respectively (Fig. 2). The incidence of Grade $\geq 3$ cataract was $42 \%$ (95\% CI, 24 $55 \%$ ) for 50 patients treated with 6-MV X-rays (prescribed dose: $30-31 \mathrm{~Gy})$ and $17 \%(95 \% \mathrm{CI}, 0-42 \%)$ for 8 patients treated with $9-\mathrm{MeV}$ electrons (prescribed dose: $30 \mathrm{~Gy})$; the difference was not significant $(P=0.59)$. The median age at the start of RT for patients with Grade 3 cataract was 67 years (range, 50-80 years). Of the 9 patients who received RT on both eyes, 5 were treated with 6-MV X-rays or 9-MeV electrons without a lens shield. Of them, one patient who had received RT at 76 years old underwent bilateral cataract surgery at the same time (73 months after RT), but was diagnosed with age-

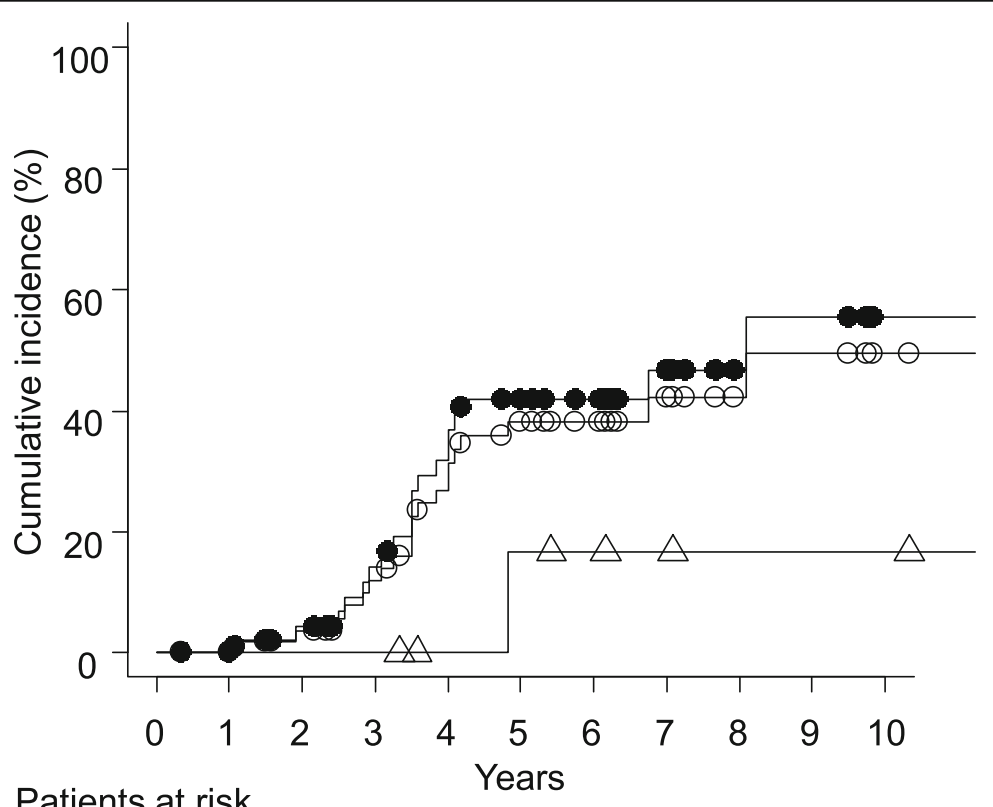

Patients at risk

$\begin{array}{llllllllllll}\text { All } & 58 & 57 & 50 & 43 & 33 & 26 & 20 & 14 & 8 & 7 & 4\end{array}$

6-MV X $\begin{array}{lllllllllll}50 & 49 & 42 & 35 & 27 & 21 & 16 & 11 & 6 & 5 & 2\end{array}$

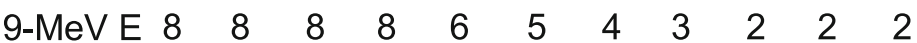

Fig. 2 Cumulative incidence of Grade $\geq 3$ cataract in all 58 patients treated without a lens shield (open circle), in 50 patients treated with 6-MV Xrays (filled circle), and in 8 patients 9-MeV electrons (triangle). The median age at the start of RT was 69 (range, 90-29), 70 (range, 90-43), and 64 (range, 88-29) years, respectively 
related cataract. One patient who had received RT at 67 years old had Grade 3 cataract on left side 30 months after RT, and another patient who had received RT at 61 years old had Grade 2 cataract on right side 69 months after RT. They did not develop cataract on the other side.

\section{Discussion}

In general, patients with MALT lymphoma have a better prognosis than those with other eye lymphomas. Olsen et al. [22] reported on 797 patients with a histologically verified orbital lymphoma and showed that extranodal marginal zone B-cell lymphoma and follicular lymphoma were associated with a markedly better prognosis (10year disease-specific survival of 92 and $71 \%$, respectively) than DLBCL and mantle cell lymphoma (10-year disease-specific survival of 41 and 32\%, respectively). Our results showed that ocular adnexal MALT lymphoma responded quite well to moderate-dose RT, with good LC and long-term survival. Similar results were shown in previous reports. Joo et al. [23] treated 134 MALT lymphoma patients using definitive RT. Among the 88 orbital MALT lymphoma patients, the median dose was $30.6 \mathrm{~Gy}$. The 5-year LC and relapse-free survival (RFS) rates were 94 and $80 \%$, respectively. Harada et al. [24] treated 86 patients with histologically proven Stage I primary ocular adnexal MALT lymphoma. The median dose was $30 \mathrm{~Gy}$. The 5- and 10-year OS rates were 97.6 and $93.5 \%$, and the 5- and 10-year local RFS were 97.0 and $90.8 \%$, respectively. Ohga et al. [25] treated 73 patients with Ann Arbor stage IE ocular adnexal MALT lymphoma. The median dose was $30 \mathrm{~Gy}$. The 5-years LC and PFS were 100 and 81.5\%, respectively.

In our study, no local relapse was observed. Although local relapse was suspected in 3 patients after RT, 2 patients were diagnosed by biopsy with IgG4-related inflammation and 1 patient with intense inflammatory cell infiltration. One of the 2 patients diagnosed with IgG4related inflammation developed DLBCL of the right parotid gland and right lung 4 years later. We did not include this patient in the events for local or distant relapse of MALT lymphoma, but there might have been DLBCL with a background of MALT lymphoma at the time of diagnosis or it might have been large cell transformation of MALT lymphoma. There have been some reports of large cell transformation in gastric MALT lymphoma, but such transformation in ocular adnexal MALT lymphoma is rare [26]. Because MALT lymphoma and IgG4-related diseases are immunohistochemically similar [27], we should be careful when local relapse is suspected.

Although the LC rate has been reported to be over $95 \%$, distant relapse occurs in $8-23 \%$ and local RT might not be useful in preventing distant relapse [12, 13, 28, 29]. Tsang et al. [13] showed that RT alone yielded excellent LC with infrequent long-term toxicity, but the risk of distant relapse was a problem. For the management of MALT lymphoma, systemic disease control with initial chemotherapy in addition to LC may be controversial. The benefit of combining RT and chemotherapy has not been investigated well in localized MALT lymphoma. Hashimoto et al. [30] showed that the combination of RT and rituximab tended to lead to better RFS than RT alone. However, MALT lymphoma has a good prognosis after initial treatment with RT alone, and we think that upfront chemotherapy is not mandatory and can be considered as salvage treatment at relapse. If relapse is limited to a few lesions, RT may be considered as an option alternative to chemotherapy. Favorite sites of relapse were reported to be contralateral paired organs and distant mucosal sites rather than the primary tumor site [23, 31, 32]. We also observed relapses in the contralateral conjunctiva, fossa axillaris, hilum of lung, mediastinal lymph node, peritoneum, intestinal membrane, skin, and left hilus of kidney. There were 2 patients who relapsed in the contralateral conjunctiva. In the 3 patients diagnosed with distant relapse and treated with chemotherapy, 2 patients treated with $\mathrm{R}-\mathrm{CHOP}$ achieved complete response, but the other patient treated with rituximab alone had relapse in the mediastinum. Our results showed that R-CHOP was effective for distant relapse. Long-term observation with careful attention to relapse at distant sites is necessary.

Regarding adverse events, the incidences of Grade $\geq 2$ and $\geq 3$ cataract were 40 and $38 \%$, respectively. Previous studies showed that more than half of patients receiving RT without a lens shield had cataract within 3-9 years following RT. [ 30, 33] Cataract is the most common late morbidity in ocular adnexal MALT lymphoma patients treated with RT. The risk of cataract and the latent period between RT and appearance of cataract are dose dependent. Emami et al. [34] estimated TD 5/5 (probability of $5 \%$ complication within 5 years from RT) of the lens for Grade $\geq 3$ cataract to be $10 \mathrm{~Gy}$ and TD 50/5 (probability of $50 \%$ complication within 5 years from RT) to be $18 \mathrm{~Gy}$. In our study, the lens of most patients treated with 6-MV photon beams received about $95 \%$ of the prescribed dose, i.e., 29 Gy with a 1.9 Gy daily dose, and those treated with $9-\mathrm{MeV}$ electron beams received about $80 \%$ of the prescribed dose, i.e., 24 Gy with a 1.6 Gy daily dose. Thus, the observed incidence of Grade $\geq 3$ cataract was lower than expected. To our knowledge, the cumulative incidences of cataracts for X-rays and electrons with estimated absorbed doses in the lens have not been reported. Accumulation of such data may lead to revision of the probability of complications from RT. The median time between RT and the appearance of Grade 3 cataract was 3.5 years (range, $1.1-8.1$ years) and 
thus longer follow-up of more than 5 years is needed. Park et al. [19] showed that consideration of RT-related factors such as lens protection and RT dose may reduce the risk of radiation-induced cataract. In cataract surgery, the cloudy lens is removed and an intraocular lens is inserted. Invasiveness of the surgery is mild, and facilities that can perform the operation as day surgery are increasing. When the lesion is close to the lens, we can irradiate the target with the appropriate dose rather than using a lead lens block to protect the lens.

Treatment options for ocular adnexal MALT lymphoma include systemic therapies such as chemotherapy and antibiotics in addition to local therapies such as RT and surgery. Jeon et al. [18] reported treatment outcomes of 208 patients with ocular MALT lymphoma treated by various modalities. With a median follow-up period of 70 months, PFS was reported to be $69.7 \%$ at 13 years, and there were no differences in survival outcomes between patients treated with RT and those treated with rituximab-containing chemotherapy (PFS, about $80 \%$ at 10 years for both groups), although the latter group had more advanced stages of this disease. They suggested that chemotherapy is recommended for younger patients, and RT is recommended for older and chemotherapy-ineligible patients from the view point of late adverse events. Ferreri AJ et al. [35] treated 27 patients with ocular adnexal MALT lymphoma with oral doxycycline. Lymphoma regression was observed in 64\% of Chlamydia psittaci DNA-positive patients (seven of 11 experienced regression) and $38 \%$ of Chlamydia psittaci DNA-negative patients (6 of 16 experienced regression). In addition to RT and chemotherapy, antibiotics may be used in most ocular adnexal MALT lymphoma patients, independently of the diagnosis of Chlamydia psittaci infection [10]. Thus, our results compare favorably with those of other treatment modalities.

Generally, the total dose for conventional RT for MALT lymphoma is 30 Gy $[12,30]$. To determine a lower effective dose may be a future task in the treatment of ocular adnexal MALT lymphoma. In recent studies, excellent LC was obtained with reduced doses [36]. Tran et al. [37] reported that the 2- and 5-year LC rates were 100 and $92 \%$, respectively, using RT with $24-$ 25 Gy. Timothy et al. [38] recommended delivery of 20$30 \mathrm{~Gy}$ at $1.5-2.0 \mathrm{~Gy}$ per fraction for low-grade lymphoma. The NCCN guidelines suggested that involved site RT (24-30 Gy) is recommended for stage I-II nongastric MALT lymphomas, and lower doses for orbit involvement [39]. Recently, Pinnix et al. used ultra-lowdose (4 Gy with a 2-Gy daily dose) and 19 of 22 patients had a complete response [40]. We will consider dose reduction for this disease in the future.

This study has several limitations inherent to a retrospective design, including possible patient selection due to some variations in treatment before RT, underestimation of toxicities, variations in follow-up intervals, and lack of baseline status of cataract. Due to these limitations, our results should be interpreted with caution.

\section{Conclusions}

RT alone achieved excellent LC and long-term survival in ocular adnexal MALT lymphoma. Long-term observation with careful attention to relapse at distant sites and radiation-induced cataract is necessary. In the case that local relapse is suspected, IgG4-related disease should be carefully ruled out.

\section{Abbreviations \\ CTV: Clinical target volume; DLBCL: Diffuse large B-cell lymphoma; LC: Local control; MALT: Mucosa-associated lymphoid tissue; OS: Overall survival; PET- CT: Positron emission tomography-computed tomography; PFS: Progression- free survival; PTV: Planning target volume; R-CHOP: Rituximab, \\ cyclophosphamide, doxorubicin hydrochloride, vincristine, and prednisolone; RT: Radiation therapy; WHO: World Health Organization}

Acknowledgments

Not applicable.

Authors' contributions

MN collected clinical data, analyzed it and wrote the manuscript. SI and YS edited and corrected the manuscript. KT, NT, AM, TK, and EK consulted on study design and interpretation of the result. All authors read and approved the final manuscript.

Funding

There was no funding

Availability of data and materials

The datasets used and analysed during the current study are available from the corresponding author on reasonable request.

Ethics approval and consent to participate

We obtained permission from the local ethics committee. The name of the ethics committee that approved the study is National Hospital Organization Nagoya Medical Center Clinical Research Center. The committee's reference number is 2018-102.

Consent for publication

Not applicable.

\section{Competing interests}

The authors declare that they have no competing interests.

\section{Author details}

'Department of Radiology, Nagoya City University Graduate School of Medical Sciences, 1 Kawasumi, Mizuho-cho, Mizuho-ku, Nagoya 467-8601, Japan. ${ }^{2}$ Department of Radiology, Ikeda City Hospital, 3-1-18 Jyonan, Ikeda, Osaka 563-8510, Japan. ${ }^{3}$ Department of Radiation Oncology, National Hospital Organization Nagoya Medical Center, 4-1-1 Sannomaru, Naka-ku, Nagoya 460-0001, Japan. ${ }^{4}$ Department of Ophthalmology, National Hospital Organization Nagoya Medical Center, 4-1-1 Sannomaru, Naka-ku, Nagoya 460-0001, Japan

Received: 18 September 2019 Accepted: 21 January 2020

Published online: 30 January 2020

References

1. Isaacson P, Wright DH. Malignant lymphoma of mucosa-associated lymphoid tissue. A distinctive type of B-cell lymphoma. Cancer. 1983;52: $1410-6$. 
2. Harris NL, Jaffe ES, Stein H, Banks PM, Chan JK, Cleary ML, et al. A revised European-American classification of lymphoid neoplasm: a proposal from the international lymphoma study group. Blood. 1994;84:1361-92.

3. Jaffe ES. The $2008 \mathrm{WHO}$ classification of lymphomas: implications for clinical practice and translational research. Hematology Am Soc Hematol Educ Program 2009:523-531.

4. Olszewski AJ, Castillo JJ. Survival of patients with marginal zone lymphoma: analysis of the surveillance, epidemiology, and end results database. Cancer. 2013;119:629-38.

5. The Non-Hodgkin's Lymphoma Classification Project. A clinical evaluation of the international lymphoma study group classification of non-Hodgkin's lymphoma. Blood. 1997;89:3909-18.

6. Anderson JR, Armitage JO, Weisenburger DD. Epidemiology of the nonHodgkin's lymphomas: distributions of the major subtypes differ by geographic locations. Non-Hodgkin's Lymphoma Classification Project. Ann Oncol. 1998;9:717-20.

7. Armitage JO, Weisenburger DD. New approach to classifying non-Hodgkin's lymphomas: clinical features of the major histologic subtypes non-Hodgkin's lymphoma classification project. J Clin Oncol. 1998;16:2780-95.

8. Zucca E, Bertoni F, Roggero E. Cavalli F. The gastric marginal zone B-cell lymphoma of MALT type. Blood 2000;96:410-419.

9. Ferreri AJ, Guidoboni M, Ponzoni M, De Conciliis C, Dell'Oro S, Fleischhauer $K$, et al. Evidence for an association between chlamydia psittaci and ocular adnexal lymphomas. J Natl Cancer Inst. 2004;96:586-94.

10. Collina F, De Chiara A, De Renzo A, De Rosa G, Botti G, Franco R. Chlamydia psittaci in ocular adnexa MALT lymphoma: a possible role in lymphomagenesis and a different geographical distribution. Infect Agent Cancer. 2012;7:8.

11. Moslehi R, Devesa SS, Schairer C, Fraumeni JF Jr. Rapidly increasing incidence of ocular non-hodgkin lymphoma. J Natl Cancer Inst. 2006;98: 936-9.

12. Goda,JS, Gospodarowicz M, Pintilie M, Wells W, Hodgson DC, Sun A, et al. Long-term outcome in localized extranodal mucosa-associated lymphoid tissue lymphomas treated with radiotherapy. Cancer 2010;116:3815-3824.

13. Tsang RW, Gospodarowicz MK, Pintilie M, Wells W, Hodgson DC, Sun A, et al. Localized mucosa-associated lymphoid tissue lymphoma treated with RT has excellent clinical outcome. J Clin Oncol. 2003;21:4157-64.

14. Parsonnet J, Hansen S, Rodriguez L, Gelb AB, Warnke RA, Jellum E, et al. Helicobacter pylori infection and gastric lymphoma. N Engl J Med. 1994;330: 1267-71.

15. Zucca E, Bertoni F, Roggero E, Bosshard G, Cazzaniga G, Pedrinis E, et al. Molecular analysis of the progression from helicobacter pylori - associated chronic gastritis to mucosa-associated lymphoid-tissue lymphoma of the stomach. N Engl J Med. 1998;338:804-10.

16. Bayerdorffer E, Neubauer A, Rudolph B, Thiede C, Lehn N, Eidt S, et al. Regression of primary gastric lymphoma of mucosa-associated lymphoid tissue type after cure of helicobacter pylori infection. MALT Lymphoma Study Group. Lancet. 1995;345:1591-4

17. Derringer GA, Thompson LD, Frommelt RA, Bijwaard KE, Heffess CS, Abbondanzo SL. Malignant lymphoma of the thyroid gland: a clinicopathologic study of 108 cases. Am J Surg Pathol. 2000:24:623-39.

18. Jeon YW, Yang HJ, Choi BO, Jung SE, Park KS, O JH. Comparison of selection and long-term clinical outcomes between chemotherapy and radiotherapy as primary therapeutic modality for ocular adnexal MALT Iymphoma. EClinicalMedicine. 2018;4-5:32-42.

19. Park HH, Lee SW, Sung SY, Choi BO. Treatment outcome and risk analysis for cataract after radiotherapy of localized ocular adnexal mucosa-associated lymphoid tissue (MALT) lymphoma. Radiat Oncol. 2017;35:249-56.

20. Cho WK, Lee SE, Paik JS, Cho SG, Yang SW. Risk potentiality of frontline radiotherapy associated cataract in primary ocular adnexal mucosaassociated lymphoid tissue lymphoma. Korean J Ophthalmol. 2013;27:243-8.

21. Kanda Y. Investigation of the freely-available easy-to-use software "EZR" for medical statistics. Bone Marrow Transplant. 2013;48:452-8.

22. Olsen TG, Holm F, Mikkelsen LH, Rasmussen PK, Coupland SE, Esmaeli B, et al. Orbital lymphoma-an international multicenter retrospective study. Am J Opthalmol. 2019;119:44-57.

23. Joo JH, Lee SW, Huh J, Suh C, Yoon DH, Ahn SD, et al. Recurrence patterns of mucosa-associated lymphoid tissue lymphoma after definitive radiation treatment: a single center experience. Hematology. 2016;21:542-8.

24. Harada K, Murakami N, Kitaguchi M, Sekii S, Takahashi K, Yoshio K, et al. Localized ocular adnexal mucosa-associated lymphoid tissue lymphoma treated with RT: a long-term outcome in 86 patients with 104 treated eyes. Int J Radiat Oncol Biol Phys. 2014;88:650-4.

25. Ohga S, Nakamura K, Shioyama Y, Sasaki T, Yamaguchi T, Yoshitake T, et al. Treatment outcome of radiotherapy for localized primary ocular adnexal MALT lymphoma - prognostic effect of the AJCC tumor-node-metastasis clinical staging system. Anticancer Res. 2015;35:3591-8.

26. Yoshino T, Akagi T. Gastric low-grade mucosa-associated lymphoid tissue lymphomas: their histogenesis and high-grade transformation. Pathol Int. 1998:48:323-31.

27. Krzysztof O, Jacek S, Wojciech S, Okoń K, Leszczyńska J, Bojanowska E, et al. Immunoglobulin G4-related disease (lgG4-RD) in the orbit: mucosaassociated lymphoid tissue (MALT)-type lymphomas. Med Sci Monit. 2015 21:1043-50

28. Hitchcock S, Ng AK, Fisher DC, Silver B, Bernardo MP, Dorfman DM, et al. Treatment outcome of mucosa-associated lymphoid tissue/marginal zone non-Hodgkin's lymphoma. Int J Radiat Oncol Biol Phys. 2002;52:1058-66.

29. Le QT, Eulau SM, George TI, Hildebrand R, Warnke RA, Donaldson SS, et al. Primary radiotherapy for localized orbital MALT Iymphoma. Int J Radiat Oncol Biol Phys. 2002;52:657-63.

30. Hashimoto N, Sasaki R, Nishimura H, Yoshida K, Miyawaki D, Nakayama M, et al. Long-term outcome and patterns of failure in primary ocular adnexal mucosa-associated lymphoid tissue lymphoma treated with radiotherapy. Int J Radiat Oncol Biol Phys. 2012;82:1509-14.

31. Cahill M, Barnes C, Moriarty P, Daly P, Kennedy S. Ocular adnexal lymphoma-comparison of MALT lymphoma with other histological types. $\mathrm{Br}$ J Ophthalmol. 1999:83:742-7.

32. Tsang RW, Gospodarowicz MK, Pintilie M, Bezjak A, Wells W, Hodgson DC, et al. Stage I and II MALT lymphoma: results of treatment with radiotherapy. Int J Radiat Oncol Biol Phys. 2001;50:1258-64.

33. Fukutsu K, Kase S, Ishijima K, Kinoshita R, Ishida S. The clinical features of radiation cataract in patients with ocular adnexal mucosa-associated lymphoid tissue lymphoma. Radiat Oncol. 2018;13:95.

34. Emami B, Lyman J, Brown A, Coia L, Goitein M, Munzenrider JE, et al. Tolerance of normal tissue to therapeutic irradiation. Int J Radiat Oncol Biol Phys. 1991;21:109-22.

35. Ferreri AJ, Ponzoni M, Guidoboni M, Resti AG, Politi LS, Cortelazzo S, et al. Bacteria-eradicating therapy with doxycycline in ocular adnexa MALT Iymphoma: a multicenter prospective trial. J Natl Cancer Inst. 2006;98:1375-82.

36. Yahalom J, Illidge T, Specht L, Hoppe RT, Li YX, Tsang R, et al. Modern radiation therapy for extranodal lymphomas: field and dose guidelines from the international lymphoma radiation oncology group. Int J Radiat Oncol Biol Phys. 2015;92:11-31

37. Tran KH, Campbell BA, Fua T, MacManus M, Ryan G, Chesson B, et al. Efficacy of low dose radiotherapy for primary orbital marginal zone Iymphoma. Leuk Lymphoma. 2013:54:491-6.

38. Bolek TW, Moyses HM, Marcus RB Jr, Lightsey J, Mendenhall WM, Mendenhall NP. Radiotherapy in the management of orbital lymphoma. Int J Radiat Oncol Biol Phys. 1999;44:31-6.

39. NCCN Guidelines Version 2. Non-Hodgkin's Lymphomas. Plymouth Meeting: National Comprehensive Cancer Network, Inc.; 2015.

40. Pinnix CC, Dabaja BS, Milgrom SA, Smith GL, Abou Z, Nastoupil L, et al. Ultla-low-dose radiation therapy for definitive management of ocular adnexal B-cell lymphoma. Head Neck. 2017;39:1095-100.

\section{Publisher's Note}

Springer Nature remains neutral with regard to jurisdictional claims in published maps and institutional affiliations. 